\title{
INFLUENCE OF LASER POWER IN DIRECT LASER DEPOSITION ON THE PROPORTION OF FERRITE AND AUSTENITE IN DUPLEX STEEL SAF2507
}

\author{
'BRÁZDA Michal, 'SALVETR Pavel, 'DLOUHÝ Jaromír, 'VAVŘíK Jaroslav \\ 1COMTES FHT - Dobřany, Czech Republic, EU, mbrazda@comteshft.cz
}

https://doi.org/10.37904/metal.2020.3517

\begin{abstract}
This work focuses on the effect of laser power on the proportion of austenite and ferrite in duplex steel SAF 2507. Duplex steels combine the advantages of ferritic and austenitic steels, preferably with an optimal proportion of austenite and ferrite. The effect of laser beam power in direct laser deposition on this proportion of microstructure constituents was studied. The proportion also has an impact on mechanical and corrosion properties, which are essential for this type of steel. Duplex steels are often used in corrosive environments and their mechanical properties and corrosion resistance depend on the proportion of austenite and ferrite. Direct laser deposition (DED) was used for making samples. DED operates on the principle of laser melting of a powder which is carried by the shielding gas into a nozzle. This technology can be used as an additive manufacturing process as well as for surface repairs and modification of components. The samples in this experimental study were printed using several different fixed outputs and the same intervals. One sample was printed using the machine's automatic mode. Microstructural analysis was performed using EBSD, EDS and light microscopy. The proportion of austenite and ferrite was measured by X-ray diffraction (XRD analysis). The differences in the proportion of ferrite and austenite were minimal, on the order of several percentage points.
\end{abstract}

Keywords: Direct Energy Deposition, duplex, SAF2507, microstructure

\section{INTRODUCTION}

Duplex steels contain a balanced proportion of ferrite and austenite. For the best mechanical properties and corrosion resistance, the optimal proportion is 1:1. These steels are most often used in the marine, petrochemical, oil, gas and shipbuilding industries. They have some of the highest chromium contents of the entire group of cast stainless steels [1,2]. The chromium levels range from 21 to $27 \%$. Corrosion resistance is further increased by alloying with molybdenum (up to $6 \%$ ) and nitrogen. With such compositions, the twophase structure is achieved by nickel additions at 5.5 to $8.5 \%$. Nickel is one of the austenite-forming elements that compensate for the high content of ferrite-forming elements (chromium, molybdenum). If a certain proportion of ferrite and austenite contents is to be achieved, the levels of ferrite-forming and austenite-forming elements must be balanced as well. A small change in the composition can cause a significant change in the resulting microstructure and thus in the properties of the steel. However, the proportion of both constituents depends not only on the chemical composition but also on heat treatment. Duplex steels must be heat treated at temperatures above $1000^{\circ} \mathrm{C}$. Typically, with increasing temperature the ferrite content increases [3,4].

Direct energy deposition (DED) is one of the technologies for 3D additive manufacturing of metal parts. Using DED, components can be made of various materials and alloys, ranging from steels, through titanium, to nickel. Non-metallic materials, such as ceramics, can be deposited, or various non-metallic additives can be used such as carbides. One advantage of the process is its ability to deposit multiple materials at a time while building a single component or even to mix powders of different materials during the additive manufacturing process. DED is also employed to repair components and deposit coatings with different properties than the 
base material. DED melts the powder with a laser, but there are other technologies that rely on an electron beam or an electric arc. Additive manufacturing takes place under a protective atmosphere or in a vacuum, depending on the process used. Each of these technologies has its advantages and disadvantages $[5,6]$.

Additive manufacturing of duplex steels using DED has not received wide attention yet. Therefore, this method will be examined in more detail. A few reports have been published on processes that use wire arc additive manufacturing.

\section{MATERIAL AND METHODS}

The Insstek MX-600 machine was used for deposition. Its energy source is a $2 \mathrm{~kW}$ fibre-guided Ytterbium laser. The print space size is $600 \times 450 \times 350 \mathrm{~mm}(\mathrm{x} / \mathrm{y} / \mathrm{z})$. The whole process took place under a protective atmosphere of argon 4.8. A powder designated as SAF 2507 with a particle size of $45-150 \mu \mathrm{m}$ from Sandvik Osprey LTD was the feedstock material. Its chemical composition is shown in Table 1.

Table 1 Chemical composition of SAF 2507 (wt\%)

\begin{tabular}{|c|c|c|c|c|c|c|c|c|c|c|c|c|}
\hline Fe & $\mathbf{C}$ & $\mathbf{C r}$ & $\mathbf{N i}$ & $\mathbf{M o}$ & $\mathbf{M n}$ & $\mathbf{S i}$ & $\mathbf{N}$ & $\mathbf{0}$ & $\mathbf{C u}$ & $\mathbf{A l}$ & $\mathbf{P}$ & $\mathbf{S}$ \\
\hline Bal. & 0.02 & 25.2 & 7.0 & 4.02 & 0.9 & 0.5 & 0.3 & 0.05 & 0.02 & 0.01 & 0.008 & 0.006 \\
\hline
\end{tabular}

It is the stated chemical composition from the material data sheet supplied by the manufacturer. The additive manufacturing, deposition parameters were followed: module SDM 800, layer height was $250 \mu \mathrm{m}$, beam diameter corresponded to $800 \mu \mathrm{m}$. Federate was $849 \mathrm{~mm} / \mathrm{min}$, hatch distance was $0.5 \mathrm{~mm}$ and deposition strategy corresponded to ZigZag. In the process, all the parameters were constant, except of the laser power. All other parameters were the same for all samples.

A total of 5 samples were built. Their geometry was a cube with an edge length of $15 \mathrm{~mm}$. Table 2 shows the individual output levels and the resulting height in the $Z$ direction. The samples were built on a platform made of C45 steel with a size of $95 \times 95 \times 20 \mathrm{~mm}$. DMT technology (Direct Metal Tooling) is a process patented by Insstek. It controls the laser power during additive manufacturing to ensure that the layer height is constant. For this purpose, the system monitors the height of the melt using optical sensors.

Table 2 Power specification and height in Z direction for each sample

\begin{tabular}{|c|c|c|}
\hline & Power [W] & Height in Z direction [mm] \\
\hline Sample 1 & DMT & 15 \\
\hline Sample 2 & 400 & 12.7 \\
\hline Sample 3 & 500 & 14.5 \\
\hline Sample 4 & 600 & 15.6 \\
\hline Sample 5 & 700 & 17.2 \\
\hline
\end{tabular}

The samples were then cut away from the platform and prepared for metallographic analysis. Metallographic sections were prepared by grinding and polishing. Microstructure was revealed by electrolytic etching with $20 \% \mathrm{NaOH}$ at $3.2 \mathrm{~V}$ for 15 seconds. It was observed under a light microscope (Nikon ECLIPSE MA200) and in a scanning electron microscope (JEOL IT $500 \mathrm{HR}$ ) equipped with an EDS analyser (EDAX Octane Elite Super). EDS was used for determining the chemical composition of phases. The EBSD camera (EDAX Hikari Super) provided information on grain orientation. The proportion of ferrite and austenite was measured by $\mathrm{X}$ ray diffraction (Bruker D8 Discover) on an area of $6 \times 10 \mathrm{~mm}$ on samples ground with P1200 paper. 


\section{RESULTS}

\subsection{Austenite and ferrite proportion}

The samples were built using fixed power levels spaced at $100 \mathrm{~W}$ between $400 \mathrm{~W}$ and $700 \mathrm{~W}$. One additional sample was printed using the DMT mode. The DMT mode maintains a constant layer height. The laser power varied in the range of about $400 \mathrm{~W}$ to $600 \mathrm{~W}$. The effect of the change in laser power on phase fraction is up to $10 \%$. Sample 3 contained no less than $30 \%$ of austenite. The largest amount of austenite was found in sample 5 , specifically $38 \%$. Samples 2 and 4 had approximately equal proportions of austenite and ferrite. Table 3 presents the dependence of height in $Z$ direction on the deposition power. There is a fluctuating trend in the content of ferrite and austenite in the duplex steel. If the ferrite content dropped at the power level above $700 \mathrm{~W}$, other parameters would have to be adjusted to avoid collision of the nozzle with the sample. The measured values were followed: in sample $131 \%$ of austenite $(A)$ and $69 \%$ of ferrite $(F)$ was found. In sample 2 it was $35 \%$ of austenite and $65 \%$ of ferrite, in sample $330 \%$ of austenite and $70 \%$ of ferrite, while in sample 4 was $35 \%$ of austenite and $65 \%$ of ferrite. In sample 5 was $38 \%$ of austenite and $62 \%$ of ferite.

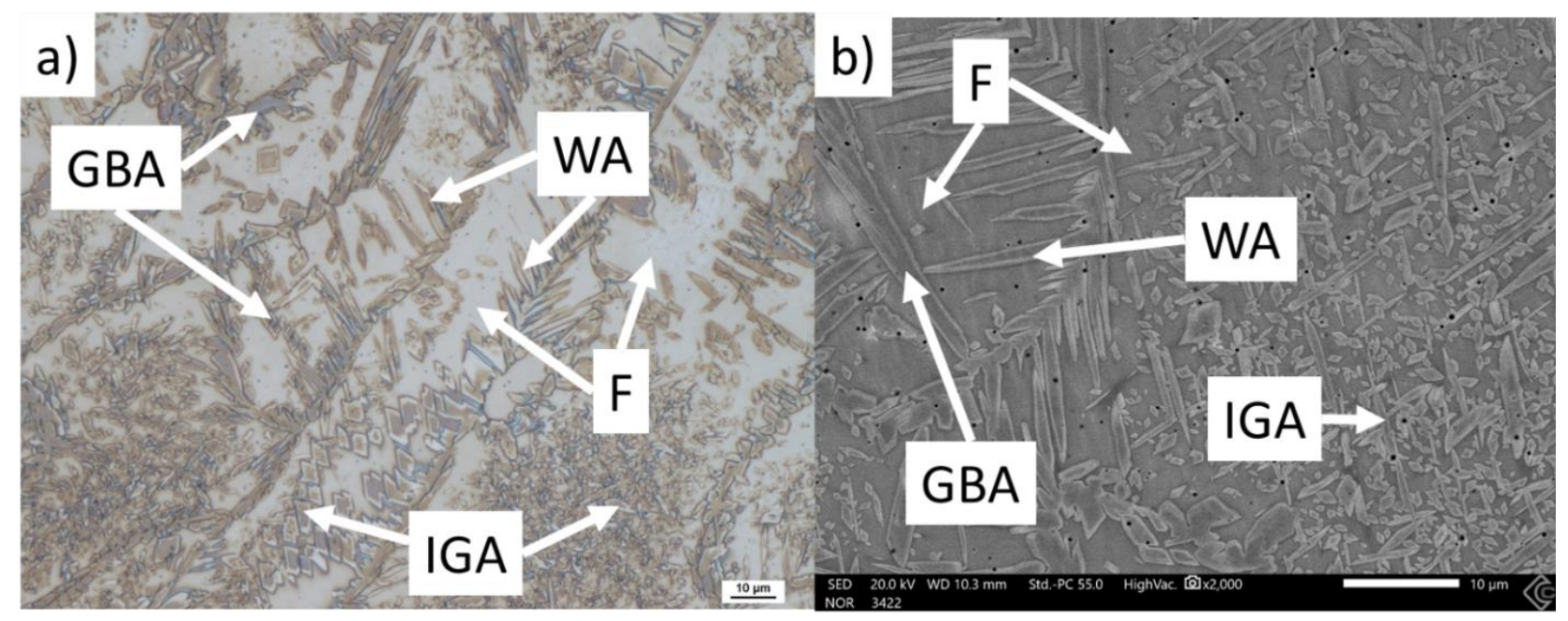

Figure 1 Type of austenite in SAF 2507, a) LM (sample 1), b) SEM (sample 3)

\subsection{Microstructure}

The microstructure corresponds to the results of XRD, which only detected ferrite $(F)$ and austenite $(A)$. There are three types of austenite in this microstructure. Each type of austenite forms at different temperatures. Ferrite grains in the etched samples stretched across several layers of the build. Along ferrite grain boundaries, there was grain boundary austenite (GBA), and thin needles of Widmanstätten austenite (WA), both in Figure 2, growing from the ferrite grain boundaries. Meltpool boundaries are lined with heat affected zones (HAZ) where the largest amount of austenite was the form of intergranular austenite (IGA), see Figure 1 $[2,7,8]$. Figure 1a) shows light micrographs (LM) and Figure 1b) scanning electron micrographs (SEM). Figure 2a) reveals that the lower-lying layers underwent rapid cooling in the temperature range of 500 to $600{ }^{\circ} \mathrm{C}$ thanks to heat dissipation to the platform $[3,9,10]$. For this reason, the centre of the melt pool is free of IGA and the HAZ is formed along the melt pool boundaries where the temperature for the formation of IGA is favourable. With increasing height of the build the width of the HAZ is increased (Figure 2a)) due to less heat dissipation from the sample. This can also be seen along the edges of the sample. In the last three or four layers in samples 1 to 4 , the gas flow from the nozzle accelerated cooling more strongly. Hence, the last few layers have experienced weaker thermal effects from their overlaying layers. As a result, IGA was not found in them. Figure 2b) shows the HAZ around the melt pools which was also affected by the deposition parameters. 

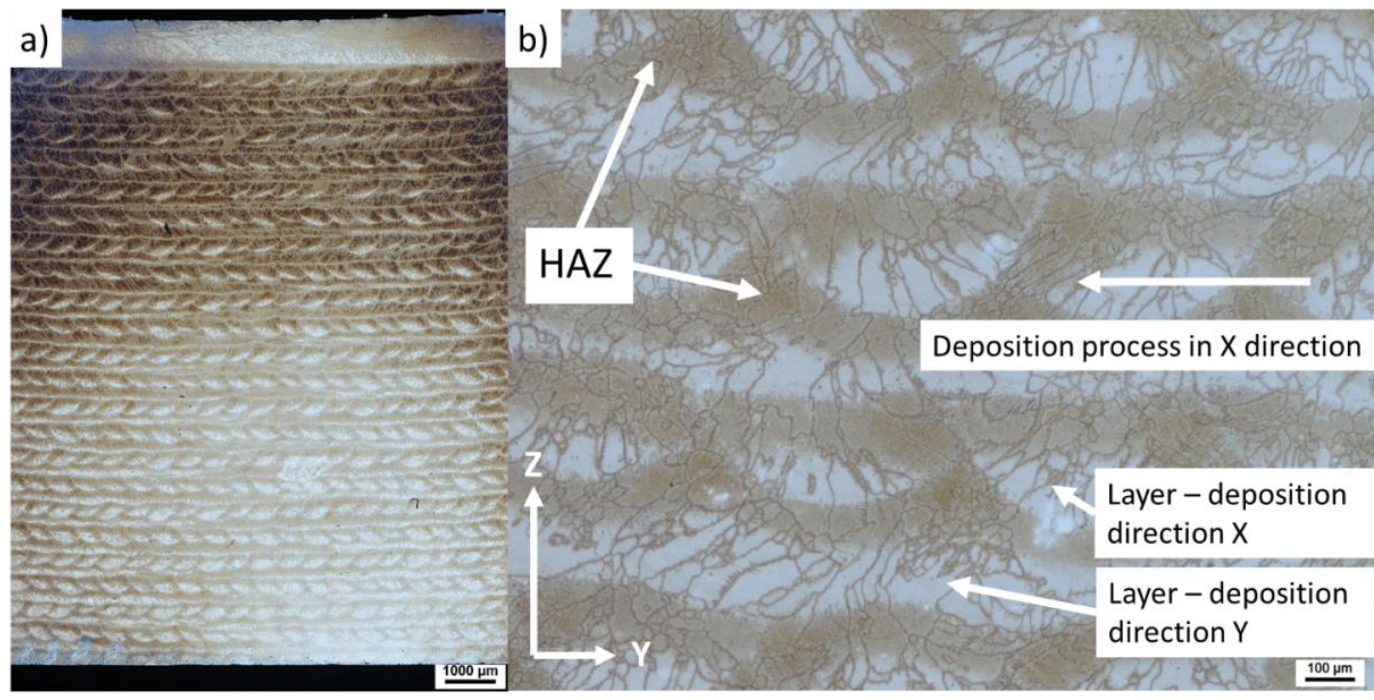

Figure 2 Sample 4: a) the entire sample, b) a detail view with a description of the additive manufacturing process

Table 3 Elemental analysis of sample 2 (wt\%)

\begin{tabular}{|c|c|c|c|c|c|c|c|}
\hline Spot & $\mathbf{1}$ & $\mathbf{2}$ & $\mathbf{3}$ & $\mathbf{4}$ & $\mathbf{5}$ & $\mathbf{6}$ & $\mathbf{7}$ \\
\hline Mo L & 2.1 & 2.3 & 2.5 & 2.2 & 2.9 & 2.4 & 2.8 \\
\hline Cr K & 29.1 & 28.8 & 29.0 & 29.4 & 29.0 & 29.1 & 29.3 \\
\hline Mn K & 1.2 & 1.6 & 1.5 & 1.2 & 1.5 & 1.2 & 1.5 \\
\hline Fe K & 61.6 & 61 & 61.4 & 61.0 & 61.0 & 61.6 & 60.9 \\
\hline Ni K & 6.0 & 6.3 & 5.6 & 6.2 & 5.6 & 5.7 & 5.5 \\
\hline
\end{tabular}

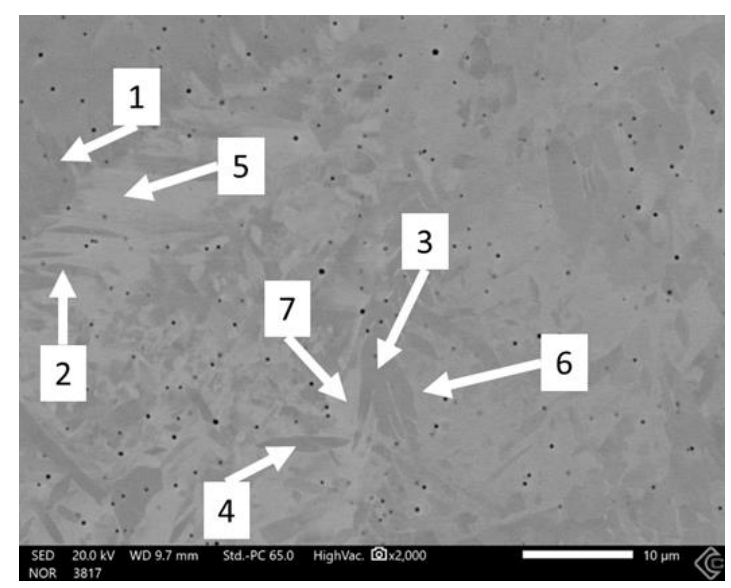

Figure 3 Locations of EDS measurement (sample 2, polished)

\subsection{EBSD and EDS analysis}

EDS (Energy Dispersive X-Ray Spectroscopy) analysis did not reveal any significant segregation of elements. The measured values are listed in Table 3. The locations studied are shown in Figure 3. Austenite was detected in spots 1-4 and ferrite was observed in spots $5-7$. The differences in the levels of ferrite-forming and austenite-forming elements are very low, up to half a percentage points. The observed microstructure may have been affected by temperature. 

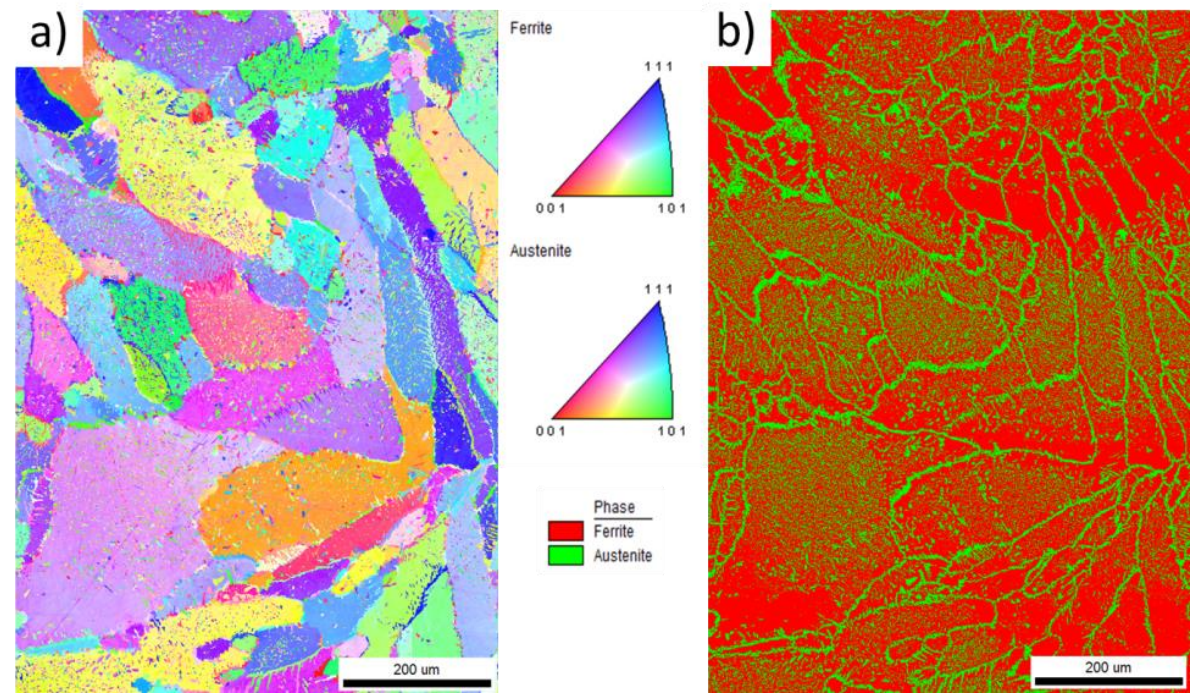

Figure 4 EBSD analysis a) IPF orientation map, b) phase map of ferrite and austenite distribution
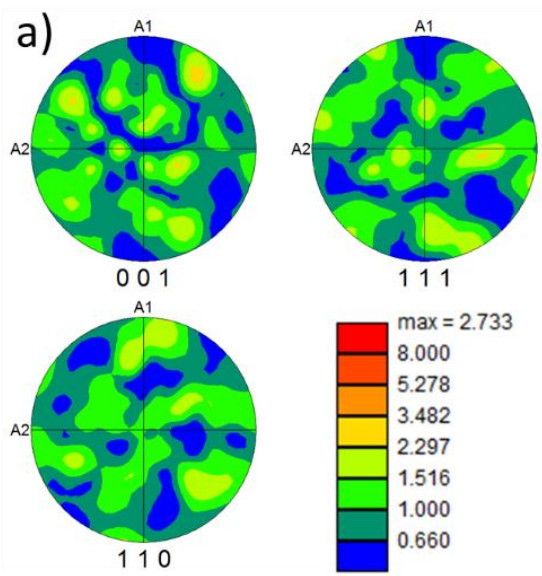

b)

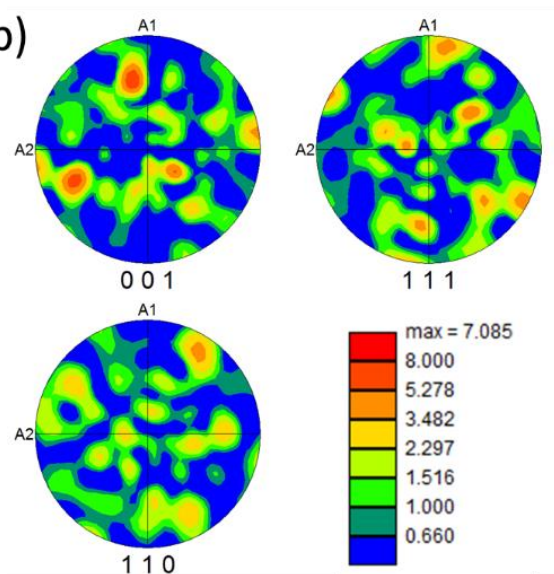

Figure 5 Pole figures: a) austenite, b) ferrite

Figure 4 shows IPF orientation map and phase map of ferrite and autenite distribution. The pole figures from EBSD data are shown in Figure 5. No preferential orientation was found in either of the phases. The texture intensity was higher in ferrite grains than in austenite ones. Figure 5a) shows austenite grains and Figure 5) ferrite grains.

\section{CONCLUSION}

This paper explores the effect of laser power in direct laser deposition on the proportion of austenite and ferrite in SAF 2507 super duplex steel. Additive manufacturing of super duplex steels can be performed using different power settings. The effect of the laser power on the proportion of austenite and ferrite was found to be minimal. The amount of ferrite was higher than that of austenite and exceeded the expected value of $50 \%$. The austenite content ranged from $29.5 \%$ to $38.2 \%$, with the largest fraction of austenite found in sample 5 . It was measured using XRD. Ferrite grains grew across several layers deposited by additive manufacturing. Austenite was found in three different modifications: intergranular austenite (IGA), Widmanstätten austenite (WA) and grain boundary austenite (GBA). GBA and WA were present along the boundaries of ferrite grains. IGA occurred mostly along the melt pool boundaries where distinct HAZ was observed. As the sample was being built, the width of the HAZ increased, too. IGA in the HAZ was not found in several topmost layers of the 
sample, except in sample 5. This may have been caused by the highest thermal input to the sample and by the heated platform, which provided austenite with sufficient time to precipitate. EDS analysis did not identify any significant differences in the concentrations of individual elements which could be suspected to affect the formation of IGA in the HAZ. EBSD analyses showed the distribution of austenite and ferrite. The grains were distributed randomly and no preferential grain growth was observed. Austenite grains have been found to have a finer structure than the ferrite ones. The formation of IGA may have been caused by thermal effects, such as heat dissipation into the sample and the differences in the thermal gradient within the sample during the additive process. The reasons for formation of IGA will explored in further research.

\section{ACKNOWLEDGEMENTS}

This paper was developed thanks to the project of Pre-Application Research of Functionally Graduated Materials by Additive Technologies, No.: CZ.02.1.01/0.0/0.0/17_048/0007350, financed by the Ministry of Education of the Czech Republic.

\section{REFERENCES}

[1] ZHANG, Z., ZHAO, H., ZHANG, H., HU, J., JIN, J. Microstructure evolution and pitting corrosion behavior of UNS S32750 super duplex stainless steel welds after short-time heat treatment. Corrosion Science. 2017, vol. 121, pp. 22-31.

[2] SARAVANAN, S., RAGHUKANDAN, K., SIVAGURUMANIKANDAN, N. Pulsed Nd: YAG laser welding and subsequent post-weld heat treatment on super duplex stainless steel. Journal of Manufacturing Processes. 2017, vol. 25, pp. pp. 284-289.

[3] ZHANG, X., WANG, K., ZHOU, Q., DING, J., GANGULY, S., MARZIO, M., YANG, D., XIANGFANG, X., DIRISU, P., WILLIAMS, S.W. Microstructure and mechanical properties of TOP-TIG-wire and arc additive manufactured super duplex stainless steel (ER2594). Materials Science and Engineering A. 2019, vol. 762, no. 13897.

[4] EGHLIMI, A., SHAMANIAN, M., RAEISSI, K. Effect of current type on microstructure and corrosion resistance of super duplex stainless steel claddings produced by the gas tungsten arc welding process. Surface and Coatings Technology. 2014, vol. 244, pp. 45-51.

[5] SOSHI, M., YAU, C., KUSAMA, R. Development and evaluation of a dynamic powder splitting system for the directed energy deposition (DED) process. CIRP Annals, 2020.

[6] GU, D. Laser Additive Manufacturing of High-Performance Materials. Nanjing: Springer, 2015.

[7] ZHANG, Y., CHENG, S., WU, S., CHENG, F. The evolution of microstructure and intergranular corrosion resistance of duplex stainless steel joint in multi-pass welding. Journal of Materials Processing Technology. 2020, vol. 277 , no. 116471.

[8] SINGH, J., SHAHI, A.S. Metallurgical and corrosion characterization of electron beam welded duplex stainless steel joints. Journal of Manufacturing Processes.2020, vol. 50, pp. 581-595.

[9] ZHANG, Z., ZHANG, H., HU, J., QI, X., BIAN, Y., SHEN, A., XU, P., ZHAO, Y. Microstructure evolution and mechanical properties of briefly heat-treated SAF 2507 super duplex stainless steel welds. Construction and Building Materials.. 2018, vol. 168, pp. 338-345.

[10] HEJRIPOUR, F., BINESH, F., HEBEL, M., AIDUN, A.D.K. Thermal modeling and characterization of wire arc additive manufactured duplex stainless steel. Journal of Materials Processing Technology. 2019, vol. 272, pp. 5871. 